\title{
Variation Characteristics and Influencing Factors on the Number of Livestock in the Hohhot Area from 1986 to 2015
}

\author{
Bojie Yan ${ }^{1 *}$, Jingjie Yan², Wenjiao Shi ${ }^{3}$, Yaxing $\mathrm{Li}^{4}$ \\ ${ }^{1}$ Ocean College, Minjiang University, Fuzhou, China \\ ${ }^{2}$ College of Telecommunications and Information Engineering, Nanjing University of Posts \\ and Telecommunications, Nanjing, China \\ ${ }^{3}$ Key Laboratory of Land Surface Pattern and Simulation, Institute of Geographic Sciences \\ and Natural Resources Research, CAS, Beijing, China \\ ${ }^{4}$ Spatial Information Research Center of Fujian Province, Fuzhou University, Fujian, China
}

Received: 2 May 2019

Accepted: 21 August 2019

\begin{abstract}
The variation characteristics of the number of livestock in Hohhot for the past 30 years were studied to determine the main factors affecting the number of livestock and realize the rapid and sustainable development of animal husbandry. The correlation among livestock, climate, and socio-economic factors in Hohhot was determined by a correlation analysis method. Moreover, the quantitative relationship among livestock, climate, and socio-economic factors in Hohhot was determined by the regression analysis method. Results corroborate that the number of cattle and sheep increased as a whole, whereas the number of horses, donkeys, and mules decreased gradually from 1996 onwards. In addition, the number of pigs increased from 1986 to 1999, decreased from 1999 to 2004, and slightly increased after 2004 and 2007.The correlation analysis results affirm that the number of cattle and horses was significantly correlated with air temperature, hours of sunshine, gross domestic product (GDP), population, sown area of crop, and grain yield $(\mathrm{P}<0.01)$. The number of sheep was significantly correlated with GDP, population, sown area of crop, grain yield $(\mathrm{P}<0.01)$, and air temperature $(\mathrm{P}<0.05)$, and has a significant negative correlation with hours of sunshine. Furthermore, the number of pigs was significantly correlated with air temperature, population, sown area of crop, and grain yield $(\mathrm{P}<0.01)$. The number of donkeys was significantly correlated with sown area of crop $(\mathrm{P}<0.01)$, air temperature, and grain yield $(\mathrm{P}<0.05)$, and the number of mules was only significantly correlated with GDP $(\mathrm{P}<0.01)$. Meanwhile, the regression analysis results contend that the effect of socio-economic factors on the variation characteristics of the number of livestock in Hohhot was greater than that of climate factors.
\end{abstract}

*e-mail: bnunercita@163.com 
Ultimately, the results could provide a scientific basis for environmental pollution control, development planning of animal husbandry, and regional economic structural readjustment.

Keywords: livestock, socio-economic factors, climate factors, correlation analysis, regression analysis

\section{Introduction}

China has one of the highest rates of animal husbandry in the world. Animal husbandry has become the most dynamic growth point and the most important pillar industry in the country's agriculture and rural economy [1-4]. Furthermore, animal husbandry is significant for safeguarding national food safety, enhancing the income of farmers, protecting the environment, and promoting the development of the national economy [4].

However, compared with that in developed countries, the proportion of animal husbandry in China's total agricultural output is still low, and the growth potential of animal husbandry is high [5]. Therefore, analyzing and determining the main influencing factors that affect animal husbandry are necessary for realizing the rapid and sustainable development of animal husbandry.

Aiming at this problem, many scholars have carried out considerable relevant research [5-11]. Combing livestock density calculated from county-level livestock data from 1982 to 1991, Yu et al. [6] estimated rainfallbased livestock carrying capacity to determine spatial and temporal patterns of a stocking rate index and its relationship with climatic factors in the Inner Mongolia Autonomous Region. Megersa et al. [8] analyzed perceptions of herders and long-term changes in cattle numbers and climate data and surveyed a total of 242 households to gain data on perceived trends in climate, rangeland condition and livestock production. Moreover, Li et al. [11] contend that the number of cattle, horses, and donkeys has a strong correlation with evaporation, annual average air temperature, and extreme hottest air temperature, and that the number of sheep only has a weak negative correlation with windy days.

The above-mentioned studies have mainly focused on the climate factors of animal husbandry. Other researchers have studied the socio-economic factors of animal husbandry [12-16]. Furthermore, Zhou et al. [12] claimed that crop area and grain yield are significantly correlated with cattle production and that grassland and forest areas are significantly correlated with sheep production by using person correlation analysis. In addition, Leng et al. [13] validated that rubber has a significant impact on the number of livestock and poultry and the planting area of corn, rice and that other economic crops have a positive impact on the number of buffalos, yellow cattle, and small-ear pigs in Southern Yunnan in the Naban River Nature Reserve. Ultimately, Zheng et al. [16] verified that the main factors affecting the number of livestock are total family income, the actual area of cultivated land, the outgoing labor force, and the average annual wage.
Meanwhile, Wang et al. [17] verified that - relative to the impact of climate change - the change of the grassland property rights system has played a leading role in the development of animal husbandry in the region after analyzing the climate change characteristics of the Hongyuan Pastoral Area and the impact of the change of the grassland property rights system on the number, structure, and survival rate of young livestock, and the mortality rate of livestock.

The above results deduce that climate, socioeconomic, and other factors have a certain impact on animal husbandry and that the development of animal husbandry in pastoral areas was more restricted by the above factors.

Hohhot is known as China's Dairy Capital. The number of cows, milk production, per capita occupancy, and consumption per capita of Hohhot rank first in China. In recent years, animal husbandry has developed rapidly, especially cow breeding. Moreover, animal husbandry has become the main pillar industry of agricultural development in Hohhot and has led to the increase of farmers' income. Although many research results indicated that climate, social-economy and other factors had a certain impact on animal husbandry, which factors had an impact on animal husbandry in Hohhot and the extent of that impact was not yet clear. Therefore, through quantitative analysis of the variation characteristics and influencing factors on the number of livestock in Hohhot for the past 30 years, we can understand the current situation of animal husbandry in Hohhot and put forward suggestions for its future development.

The objectives are the following: (i) to depict variation characteristics of the number of livestock in Hohhot from 1986 to 2015; (ii) to carry the correlation analysis on the number of livestock and climatic and socio-economic factors; and (iii) to reveal the main factors affecting the number of livestock in Hohhot.

\section{Material and Methods}

\section{Study Area}

Hohhot is located in the central part of the Inner Mongolia Autonomous Region (10 $46^{\prime}-112^{\circ} 10^{\prime} \mathrm{E}$ and $\left.40^{\circ} 51^{\prime}-41^{\circ} 8^{\prime} \mathrm{N}\right)$. The territory mainly includes the mountainous terrain in the north and southeast and the Tumochuan plain terrain in the south and southwest. Moreover, the terrain inclines gradually from northeast to southwest. The total area of Hohhot is $17,224 \mathrm{~km}^{2}$ with a total population of $3,115,000$, and it has the typical continental climate of the Mongolian Plateau, 
with evident climate change in four seasons and large annual and daily air temperature differences. The annual average air temperature in the Hohhot area is low in the north and high in the south. The annual average air temperature in the north of Daqingshan District is only about $2^{\circ} \mathrm{C}$, while that in the south is $6.7^{\circ} \mathrm{C}$. Finally, annual average precipitation is $335.2-534.6 \mathrm{~mm}$.

\section{Data Sources and Processing}

The statistical data of livestock, including cattle, horse, sheep, pig, mule and donkey, and the GDP, sown area of crop, grain yield, and population in Hohhot from 1986 to 2015 were obtained from the Statistical Yearbook of Inner Mongolia from 1987 to 2016.

The meteorological data, including precipitation, air temperature, and hours of sunshine of Hohhot from 1986 to 2015, were obtained from the China Statistical Yearbook and China Meteorological Yearbook from 1987 to 2016.

\section{Methods}

Pearson correlation analysis was done between the number of livestock and factors such as precipitation, air temperature, hours of sunshine, GDP, population, sown area of crop, and grain yield.

In addition, linear and nonlinear regression models were used to analyze the relationship between the number of livestock and factors such as precipitation, air temperature, hours of sunshine, GDP, population, sown area of crop, and grain yield. Moreover, Excel 2010 and SPSS 20.0 statistical analysis software were used for data processing and statistical analysis. The significant level was $\mathrm{P}<0.05$ or $\mathrm{P}<0.01$.

\section{Results}

Variation Characteristics of the Number of Livestock in Hohhot Area from 1986 to 2015

On the basis of the statistical data of livestock in Hohhot from 1986 to 2015, the variation characteristics of the number of livestock in Hohhot from 1986 to 2015 were procured by using Excel 2010 software (Fig. 1).

During the period of 1986 to 2015, the number of cattle increased slowly in the first decade and increased rapidly in the middle decade, but declined slowly in the latter decade. The largest and least numbers of cattle were 745,600 in 2006 and 35,700 in 1986, respectively.

In addition to the increase in 1996, the number of horses had a significant downward trend. The largest and smallest numbers of horses were 32,100 in 1986 and 1,400 in 2015.

The number of sheep increased slowly in the first decade, increased suddenly in 1996, then decreased annually, and began to increase gradually in 2003 . The largest and smallest numbers of sheep were 1,794,100 in 2015 and 330,000 in 1986, respectively.

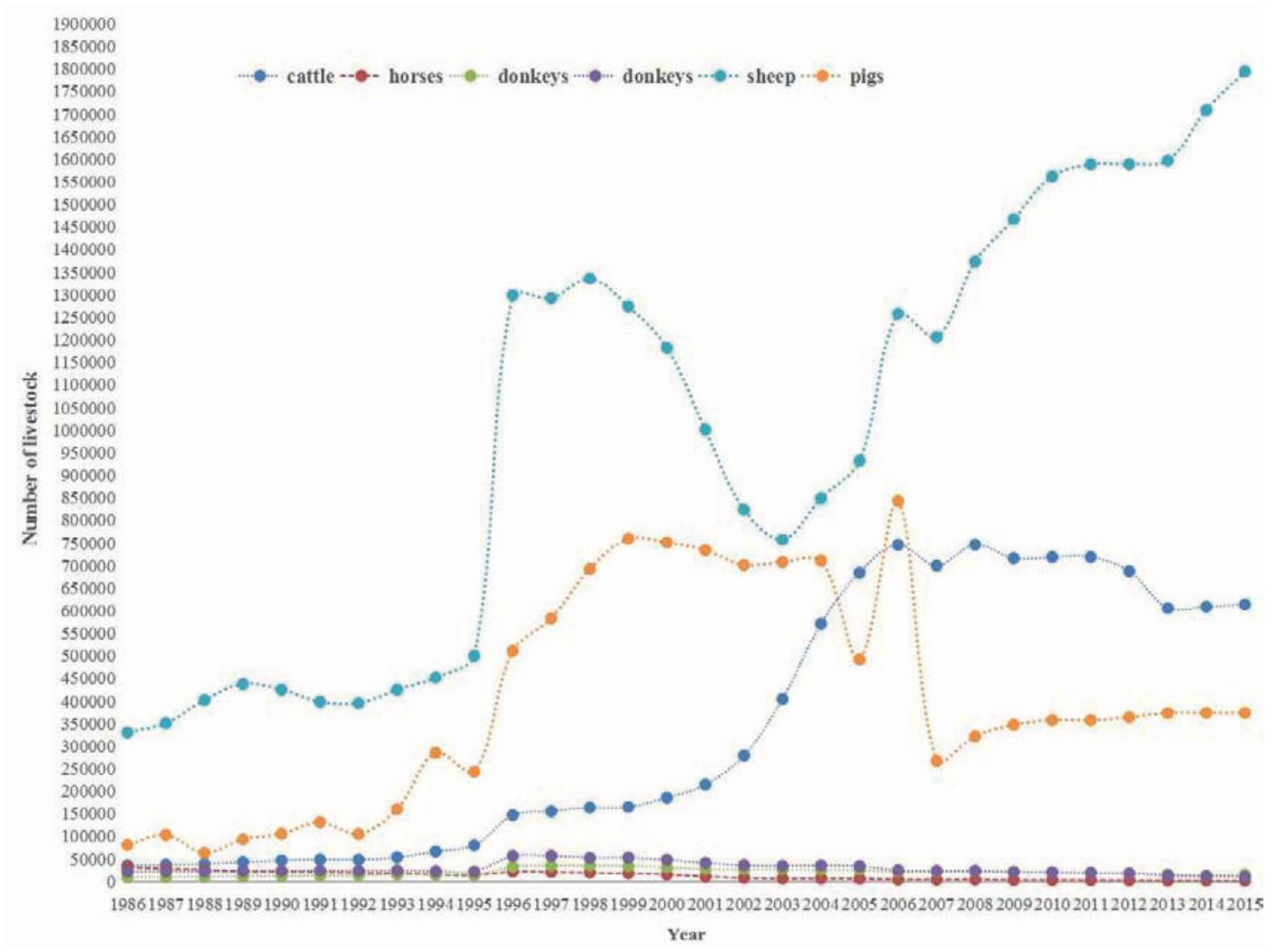

Fig. 1. Variation characteristics of the number of livestock in Hohhot in 1986-2015. 
The number of pigs kept an increasing trend from 1986 to 1999 and then maintained a slight decreasing trend until 2004. Additionally, a quick increase and decrease in the number of pigs from 2004 to 2007 and a slight increase from 2007 to 2015 emerged. The largest and smallest numbers of pigs were 842,700 in 2006, and 62,563 in 1988 , respectively.

The number of donkeys and mules had a certain similarity overall. In the first decade, the number of donkeys and mules maintained a steady and increasing trend. Moreover, in 1996, both increased sharply and then maintained a significant downward trend. The largest and smallest numbers of donkeys were 35,200 in 1998 and 8,800 in 1986, respectively, and the largest and smallest numbers of mules were 56,425 in 1997 and 10,000 in 2015, respectively.

\section{Correlation Analysis of the Number of Livestock and Climate and Socio-Economic Factors in Hohhot in 1986-2015}

On the basis of the statistical data of livestock, GDP, sown area of crop, grain yield, population, air temperature, precipitation, and hours of sunshine in Hohhot from 1986 to 2015, the correlation among livestock, climate, and socio-economic factors in Hohhot was analyzed. Table 1 exhibits the results.

The results show that the number of cattle and horses were significantly correlated with air temperature, hours of sunshine, GDP, population, sown area of crop, and grain yield $(\mathrm{P}<0.01)$, and uncorrelated with precipitation.

The number of sheep was significantly correlated with GDP, population, sown area of crop, grain yield $(\mathrm{P}<0.01)$, and air temperature $(\mathrm{P}<0.05)$. The number of sheep has significant negative correlation with hours of sunshine and is uncorrelated with precipitation.

The number of pigs was significantly correlated with air temperature, population, sown area of crop, and grain yield $(\mathrm{P}<0.01)$, and uncorrelated with precipitation, hours of sunshine, and GDP.

The number of donkeys was significantly correlated with sown area of crop $(\mathrm{P}<0.01)$, air temperature, and grain yield $(\mathrm{P}<0.05)$, and uncorrelated with precipitation, hours of sunshine, population, and GDP.

The number of mules was only significantly correlated with GDP $(\mathrm{P}<0.01)$, and uncorrelated with air temperature, population, sown area of crop, precipitation, hours of sunshine, and grain yield.

The numbers of cattle, horses, and sheep were all significantly correlated with air temperature, hours of sunshine, GDP, population, sown area of crop, and grain yield.

Regression Analysis Results of the Number of Livestock and Climate and Socio-Economic Factors in Hohhot from 1986 to 2015

The correlation among the number of livestock, climate, and socio-economic factors in Hohhot could be qualitatively obtained by correlation analysis method. But to further analyze the quantitative relationship among the number of livestock, climatic, and socioeconomic factors in Hohhot, regression analysis was needed.

The regression analysis results of non-significant correlated factors were unreliable. Therefore, the climate or socio-economic factors that significantly correlated with the number of livestock would be selected to carry out regression analysis. On this basis, regression analysis was carried out on air temperature, hours of sunshine, GDP, population, sown area of crop, and grain yield as independent variables and the number of livestock as dependent variables.

The results corroborated that the number of cattle increased with the increase in air temperature, population, GDP, sown area of crop, and grain yield. The number of cattle decreased with the increase in hours of sunshine. Furthermore, the fitting coefficients between the number of cattle and independent variables of GDP, population, sown area of crop, and grain yield were high, reaching 0.945, 0.943, 0.918, and 0.914, respectively. Ultimately, the fitting coefficients between the number of cattle and the independent variables of air temperature and hours of sunshine were low, reaching 0.286 and 0.335 , respectively.

Table 1. Correlation analysis results of livestock and climate and socio-economic factors in Hohhot in 1986-2015.

\begin{tabular}{|c|c|c|c|c|c|c|}
\hline Factors \livestock type & Cattle & Horse & Sheep & Pig & Donkey & Mule \\
\hline Air temperature & $0.470^{* *}$ & $-0.495^{* *}$ & $0.452^{*}$ & $0.566^{* *}$ & $0.455^{*}$ & 0.182 \\
\hline Precipitation & -0.022 & -0.147 & -0.008 & 0.031 & 0.017 & -0.060 \\
\hline Hours of sunshine & $-0.535^{* *}$ & $0.722^{* *}$ & $-0.495^{* *}$ & -0.290 & -0.216 & 0.161 \\
\hline GDP & $0.796^{* *}$ & $-0.783^{* *}$ & $0.797 * *$ & 0.028 & -0.130 & $-0.560^{* *}$ \\
\hline Population & $0.920^{* *}$ & $-0.892^{* *}$ & $0.917^{* *}$ & $0.465^{* *}$ & 0.335 & -0.159 \\
\hline Sown area of crop & $0.870^{* *}$ & $-0.840^{* *}$ & $0.917^{* *}$ & $0.602^{* *}$ & $0.531^{* *}$ & 0.054 \\
\hline Grain yield & $0.887^{* *}$ & $-0.870^{* *}$ & $0.903^{* *}$ & $0.535^{* *}$ & $0.455^{*}$ & -0.032 \\
\hline
\end{tabular}

**. Significant correlation at 0.01 level (bilateral), ${ }^{*}$. Significant correlation at 0.05 level (bilateral). 
The number of horses decreased with the increase of air temperature, population, GDP, sown area of crop, and grain yield, and increased with the increase of hours of sunshine. The fitting coefficients between the number of horses and the independent variables of GDP, population, sown area of crop, and grain yield were high, reaching 0.921, 0.837, 0.727, and 0.749, respectively. By contrast, the fitting coefficients between the number of horses and the independent variables of air temperature and hours of sunshine were low, reaching 0.540 and 0.550 , respectively.

The number of sheep increased with the increase of air temperature, population, GDP, sown area of crop, and grain yield, and decreased with the increase of hours of sunshine. The fitting coefficients between the number of sheep and the independent variables of GDP, population, sown area of crop, and grain yield were high, reaching $0.768,0.837,0.902$, and 0.850 , respectively. Conversely, the fitting coefficients between the number of sheep and the independent variables of air temperature and hours of sunshine were low, reaching 0.260 and 0.260 , respectively.

The number of pigs showed a decreasing trend with the increase of air temperature and grain yield. With the increase of population and sown area of crops, the number of pigs increased first and then decreased. Additionally, the fitting coefficients between the number of pigs and the independent variables of population and sown area of crop were relatively high, reaching 0.766 and 0.779 , respectively, followed by 0.606 of grain yield, and the minimum was 0.336 of air temperature.

The number of donkeys increased with the increase of air temperature and increased first and then decreased with the increase of the sown area of crop and grain yield. The fitting coefficients between the number of donkeys and the independent variables of the sown area of crop and grain yield were 0.865 and 0.705 , respectively. The fitting coefficients between the number of donkeys and air temperature were low, which was only 0.226 .

The number of mules decreased with the increase of GDP, and the fitting coefficient between the number of mules and GDP was 0.453 .

In sum, the effects of socio-economic factors including GDP, population, sown area of crop, and grain yield on the number of livestock in Hohhot were greater than climate factors, whereas the effects of climate factors such as air temperature and hours of sunshine on the number of livestock in Hohhot were general.

\section{Discussion}

With the passage of years, the numbers of cattle and sheep were increasing in general, which reflected the idea of the development of Hohhot's cattle and sheep breeding industry as the main pillar industry.

The number of horses, donkeys, and mules has gradually decreased since 1996, which was closely related to the reduction of economic and use values of horses, donkeys, and mules with the development and popularization of modern transportation. The number of pigs increased from 1986 to 1999 and decreased from 1999 to 2004. Moreover, the number of pigs confirmed a slight increase after sharply increasing and decreasing during 2004 to 2007, which indicated that the pig breeding industry changed greatly in Hohhot.

With the development thought of "stabilizing sheep, increasing cattle, and expanding pig and poultry" by the Party committees and governments of the Inner Mongolia Autonomous Region [18] and the trend of "South pig going north", the number of pigs would gradually increase in Hohhot.

The numbers of cattle, horses, and sheep were all significantly correlated with air temperature, hours of sunshine, GDP, population, sown area of crop, and grain yield. Among them, the numbers of cattle, horses, and sheep were the most relevant to the population, reaching $0.920,-0.892$, and 0.917 , respectively, which indicated that both were closely related.

The number of cattle, sheep, and pigs had a significant positive correlation with population, which was basically consistent with the fact that Hohhot was located in northern pastoral areas, with cattle and sheep breeding as mainstay industries and Hohhot's diet demand for cattle, sheep, and pig. The number of horses was negatively correlated with population, which was consistent with the fact that the number of horses was decreasing gradually [19], whereas the population was increasing gradually in Hohhot. The number of cattle and sheep had a significant positive correlation with GDP. The main reason might be that the consumption demand of cattle and mutton products increased with the increase of GDP and the improved standard of living. In turn, the increase of number of cattle and sheep would also promote the growth of GDP.

The significant negative correlation between the number of horses and mules and GDP was mainly due to the development and popularization of modern transportation. The economic and use values of horses and mules were reduced and withdrawn from herdsmen's lives [19].

In addition, the number of cattle, horses, and sheep had a significant correlation with sown area of crop and grain yield, while pigs and donkeys had the greatest correlation with sown area of crop and showed a significant correlation with grain yield, which might be because crops could provide feed for livestock; hence, cattle, horses, sheep, pigs, and donkeys had a relatively large correlation with the sown area of crops.

The above results and the results of Leng et al. [13] corroborated that the planting area of corn, rice, and other cash crops had positive effects on cattle and pigs.

The number of cattle, horses, and sheep was significantly correlated with air temperature and hours of sunshine, which were basically consistent with those of Zhuo et al. [12] on the relationship between climate 
factors such as air temperature and hours of sunshine and animal husbandry production in Naqu, Tibet.

\section{Conclusions}

The number of analyzed type of livestock varied obviously in the Hohhot area from 1986 to 2015. The results of correlation analysis showed that the number of livestock was correlated with climatic and socioeconomic factors. And the different analyzed type of livestock were correlated with different factors. The result also showed that the number of cattle, horses and sheep were significantly correlated with air temperature, sunshine hours, GDP, population, sown area of crop and grain yield. And the number of pigs was significantly correlated with temperature, population, sown area of crop and grain yield. In addition, the number of donkeys was significantly correlated with sown area of crop, temperature and grain yield. However, the number of mules was only significantly correlated with GDP.

The results of regression analysis indicated that the effect of socio-economic factors on the variation characteristics of the number of analyzed type of livestock in the Hohhot area was greater than that of climate factors.

The research results would provide a scientific basis for environmental pollution control, development planning of animal husbandry, and regional economic structural readjustment in Hohhot. However, this study did not consider factors such as feed production, per capita income, relative humidity, and evaporation, etc., which needed to be studied further due to the lack of socio-economic, climate, and other data.

\section{Acknowledgements}

This research was partly supported by the National Natural Science Foundation of China under grant Nos. 41601601 and 61501249, the Fujian Provincial Colleges and Universities Supporting Plan for Excellent Talents in the New Century in 2018 (3230412301), the Natural Science Foundation (NSF) of Jiangsu Province for Youth (BK20150855), and as a project funded by the China Postdoctoral Science Foundation (2018M632348).

\section{Conflict of Interest}

The authors declare no conflict of interest.

\section{References}

1. LIU J.J., YANG J.H., LI L.J. The development of transgenic technology and its application in animal husbandry,Genomics and Applied Biology, 36 (5), 1953, 2017.
2. PENG L., CHEN W., LI M., BAI Y., PAN Y. GIS-based study of the spatial distribution suitability of livestock and poultry farming: the case of Putian, Fujian, China. Computers \& Electronics in Agriculture, 108, 183, 2014.

3. LIU R., WANG Q., XU F., MEN C., GUO L. Impacts of manure application on swat model outputs in the xiangxi river watershed. Journal of Hydrology, 555, 479, 2017.

4. WANG G.G., WANG M.L., YANG C. Characteristics and mechanism of animal husbandry's geographical agglomeration in china. Journal of Natural Resources, 29 (12), 2137, 2014.

5. LAN Y., YAO Y.N. Analysis on animal husbandry production efficiency and regional difference in China. Journal of Central South University of Forestry \& Technology, 35 (7), 136, 2015.

6. YU M., ELLIS J.E., EPSTEIN H.E. Regional analysis of climate, primary production, and livestock density in Inner Mongolia. Journal of Environmental Quality, 33 (5), 1675, 2004.

7. ALLRED B.W., SCASTA J.D., HOVICK T.J., FUHLENDORF S.D., HAMILTON R.G. Spatial heterogeneity stabilizes livestock productivity in a changing climate. Agriculture, Ecosystems \& Environment, 193, 37, 2014

8. MEGERSA B., MARKEMANN ANDRÉ, ANGASSA A., OGUTU J.O., PIEPHO H.P., VALLE ZARÁTE ANNE Impacts of climate change and variability on cattle production in southern ethiopia: perceptions and empirical evidence. Agricultural Systems, 130, 23, 2014.

9. LACETERA N., SEGNALINI M., BERNABUCCI U., RONCHI B., VITALI A., TRAN A., GUIS H., CAMINADE C., CALVETE C., MORSE A., BAYLIS M., NARDONE A. Climate Induced Effects on Livestock Population and Productivity in the Mediterranean Area. Regional Assessment of Climate Change in the Mediterranean. Springer Netherlands, 135, 2013.

10. LUNDE T.M., LINDTJØRN B. Cattle and climate in africa: how climate variability has influenced national cattle holdings from 1961-2008. Peerj, 1 (4), e55, 2013.

11. LI Y., HE T.H., QU X.N. The study on agriculture-animal husbandry industrial adjustment in yanchi county based on its climate changes. Journal of Arid Land Resources \& Environment, 23 (12), 82, 2009.

12. ZHOU D.W., SUN H.X., ZHANG Q.Y., SONG Y.T., ZHANG Z.X. Analysis on herbivorous livestock production of China. Acta Ecologiae Animalis Domastici, 31 (6), 20, 2010.

13. LENG J., ZHANG C.X., LÜ J.Q., MAO H.M. Effects of planting rubber and crops on the keeping number of livestock and poultry in the Naban river watershed national nature reserve. Chinese Journal of Applied Ecology, 22 (10), 2693, 2011.

14. ROJAS-DOWNING M.M., NEJADHASHEMI A.P., HARRIGAN T., WOZNICKI S.A. Climate change and livestock:impacts, adaptation, and mitigation. Climate Risk Management, Climate Risk Management 16, 145, 2017.

15. BATSUURI T., WANG J. The impacts of climate change on nomadic livestock husbandry in mongolia. Climate Change Economics, 8 (3), 1, 2017.

16. ZHENG K.L., YAN J.Z., HE W.F. Influences of labor emigration from agriculture on livestock farming in mountainous areas-a case study of typical villages in Chongqing municipality. Journal of Southwest University (Natural Science Edition), 38 (4), 35, 2016. 
17. WANG Y.X., ZHENG Q.Y., YAN Z.L., TAO L.U. Institutional transition of grassland property rights and its impact on animal husbandry under the background of climate changes - a case study from eastern Qinghai-Tibet plateau. Pratacultural Science, 32 (10), 1687, 2015.

18. JIN Y.P., BAI Y., WANG J.L., BATTELLE, HONG H., SHANG R.P. An investigation of new measure for the development of animal husbandry in the Inner Mongolia
Autonomous Region in $13^{\text {th }}$ Five-Year based on the development idea of stabilizing sheep, increasing cattle and expanding pigs and poultry. Animal Husbandry and Feed Science, 38 (1), 60, 2017.

19. CONG M., WANG W.P. Analysis on current situation and modernization process of horse industry development in Inner Mongolia.Bulletin of Sport Science \& Technology, 19 (9), 16, 2011. 
